\title{
Building Parent-Teacher Partnerships as an Effective Means of Fostering Pupils' Success
}

\author{
Lenida Lekli, PhD Cand.
}

"A.Xhuvani"University, Elbasan,Albania, English and German Language Department Email:lenida_|@yahoo.com/leklilenida@gmail.com

\author{
Entela Kaloti, MA
}

"Arianiti"School,Elbasan,Albania

Email:entela.kaloti@gmail.com

Doi:10.5901/ajis.2015.v4n1s1p101

\begin{abstract}
Nowadays teachers and other school personnel are aware of problem behaviors among students stemming from different reasons. Awareness of these problems in the classroom is a first step toward preventing disruptive attitudes which are likely to negatively affect classroom environment. Educators and researchers are trying to encourage parent-teacher partnership in the 9th grade educational system as an effective means of improving students' academic success, as well as reducing behavioral problems. Teacher parent relationships can be the most critical component affecting student's learning. Thus, it is most important to get to know the family and share the accomplishment and improvements of the student. Students' learning improves when the teachers communicate with parents on a broad range of issues. Good communication is central to cooperation and support. So in recognition of the importance of parent cooperation and support of children's education, educators are calling on schools to promote partnerships with parents aiming to improve their pupils' progress. This paper aims to answer questions such as: How can schools' directories increase parental participation? What can schools do to foster positive parental involvement? How much would parental participation help in reducing behavioral problems in the classroom? Therefore building a parent-teacher partnership would be a positive solution of decreasing behavioral attitudes of students in the classroom environment.
\end{abstract}

Keywords: parents, partnership, success, participation, solution

\section{Establishing Parent-teacher Relationships}

Today's complex global societal and school environment we are living in, where teachers are frequently challenging classroom management troubles, it has become necessarily requiring to establish teacher-parent partnerships as a strategy to support students' learning. Partnership involves parents, families and practitioners working together to make children benefit from school as much as possible. "Partnership involves responsibility on both sides, teachers and parents if we want pupils to make the required progress". ("Building partnerships between parents and practitioners", n.d. p.7 ) Parental involvement includes communication between educators and parents, communication about children's homework and their difficulties, participation in school activities etc. So parent-school partnership is extraordinarily complex, including various domains.( Hornby, 2011, p.9-10)

Consequently, in today's world when we are responding to increased professional expectations, economic pressures, time constrains and rapid changes, effective collaboration between educators and parents has become more and more essential to meet the basic needs of the pupils. Parents provide children with their first learning experiences, starting with eating, sitting, walking, colouring at kindergarten, writing and reading at school etc. Since parents help their kids in establishing their basic developmental milestones in life they can also help them do well at school. Therefore reinforcing a strong parent-teacher partnership would be an indisputable strategy in guaranteeing support of their learning process in the educational institutions.

Educators of both elementary and secondary school in Albania identify "lack of discipline and presence of disruptive behaviors" (Rogers, 2003, p. 39-40) as a major problem with our public and non-public schools. Observations have reported increasing levels of antisocial behaviors among peers such as pushing and bullying. Since classroom management is a challenge educators constantly face, then techniques and strategies, one of which is also the 
establishment of parent-educator collaboration, need to be found in order to reduce these problematic attitudes.

As mentioned above, one of the most important aspects of teaching is building positive relationships with parents, as a possible strategy of improving classroom management environment. Effective parent-teacher communication is essential for a teacher to be successful, but it is also essential for a student to make progress. ("School, family and community partnerships, 2008, p.13-18) Most teachers think about having a good relationship with parents. However, just as images of teaching and learning environment vary, so do images of "good" parent-teacher relationships. At one end of the spectrum, the image of a good relationship is an effective separation of roles and functions between home and school; a separation which would influence pupils.

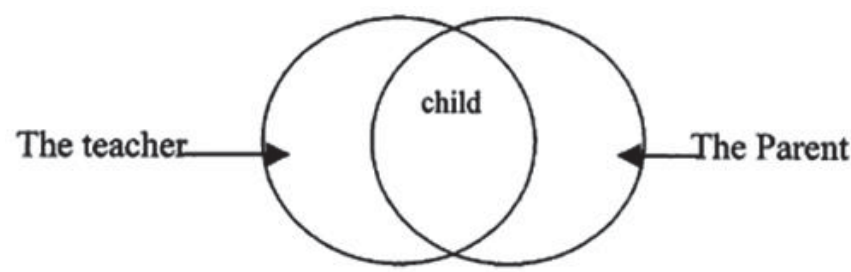

A student who knows that the teacher communicates on a regular basis with his/her parents and who knows that his/her parents trust the teacher, will likely put more effort into school. (Davis, 1995, p.23-24) Putting more efforts into school, being more hard-working and attentive to school subjects implies more concentration on the lesson, and less disruptive behaviors in the classroom which would undoubtedly negatively effect the teaching process. Likewise, a student who knows that the teacher rarely or never communicates with his/her parents, and/or his/her parents do not trust the teacher is likely to cause the opposite. So that would be counterproductive and of course it would create problems for the teachers on the management of the classroom environment and the management of the disruptive behaviors caused by pupils. But what do school directories and teachers currently do to increase parental involvement?

\section{Strategies Applied in $9^{\text {th }}$ Grade School System}

Teachers actively strive to incorporate techniques that would maximize their sharing of information, regarding pupils' progress at school, with their parents. Based on observations in the $9^{\text {th }}$ grade schools three strategies seem to be commonly practiced in our schools in Albania:

- Organization of parent-teacher meetings (once in a month, or by the end of each term)

- Frequent teacher-parent phone calls (especially in the elementary school)

- Parent-teacher notes

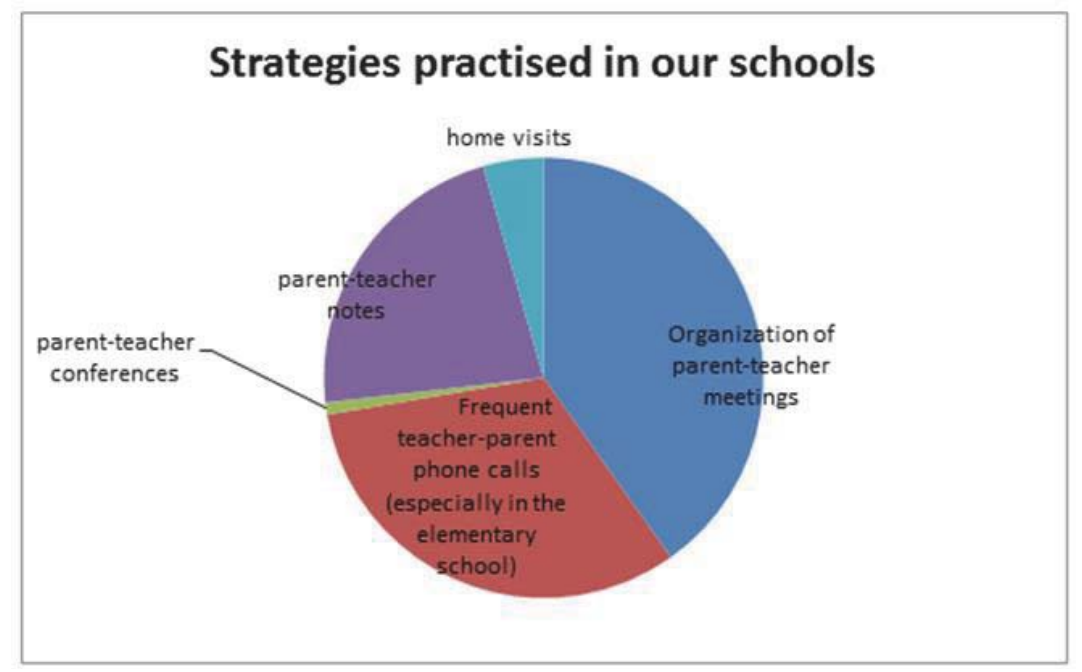

As it can be observed home visits and parent-teacher conferences are not applied by the school teachers as a possible way of increasing parent-teacher partnership, of improving students' behaviors and school progress too. Regarding the 
organization of parent-teacher meeting,(Graham, n.d., 11-14) although it is the most frequently used way of contacting students' parents, it is not always welcomed by them (parents), since not all of them do attend these preplanned school meetings. When asked about this issue, most of the teachers claimed that some parents' interest versus their child's progress seems to be decreasing, highly reflected in their absence in these events. Only $60-70 \%$ of parents do take part in these school gatherings, the rest of whom consider them as time consuming.

Applying parent-teacher notes is another successful strategy which seems to work better with the little kids, who seem to be eager in delivering these notes to their parents in order to know what their progress is according to their teachers.

Would technology be successful in achieving a good two-way communication between educators and parents? As already included in the above chart, if we talk about phones, it is to be admitted that they are a great flexible way of contacting parents and establishing a successful two way voice communication even from the classrooms when pupils are not present. Surveys have shown that a great number of teachers in Albania apply the use of cell phones in contacting with their pupils' parents, but when it comes to the use of computers (e-mails), as another technological development achieving parent-teacher collaboration, it has proved to be the least effective one due to the lack of information technology knowledge regarding the use of computers from parents, especially those over 40 years old.

However, communicating clearly and frequently with parents applying whichever possible means of communication, can help create situations that will assist parents in working more closely with their child's teacher to strengthen their learning, including even a home environment in which learning can take place effectively.

\section{What are Some of the Positive and Negative Effects of Parent-Teacher Relationships?}

Good communication skills between parents and educators is the key to motivating children's learning and their success at school. Consequently, increased children's motivation and desire in learning means more attention and engagement towards the teaching process, reducing in this way disruptive and undesirable behaviours of theirs maximizing in this way the positive climate of a well managed classroom. (Porter, 2008, p.4-5)

Therefore, parent-teacher collaboration seems to establish a strong "knot" with classroom management highly contributing to the successful ongoing of the teaching process and its positive results. Strengthening parent-teacher relationships and collaboration can have both positive and negative benefits for students:

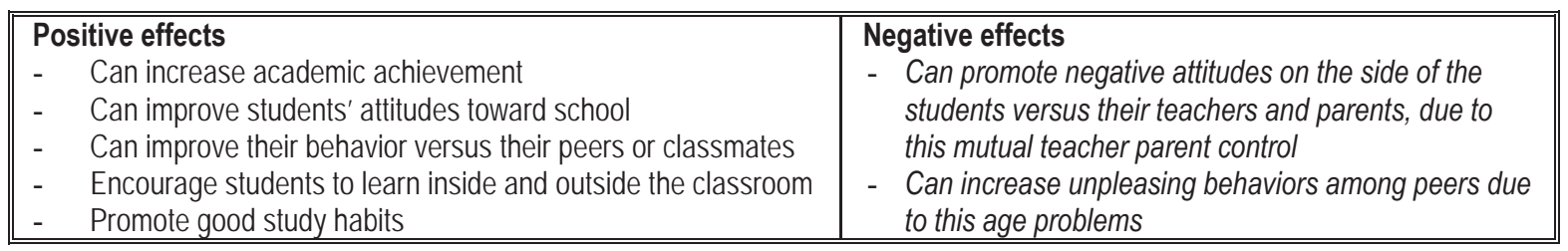

The above mentioned negative effects are mostly evident in the $7^{\text {th }}, 8^{\text {th }}, 9^{\text {th }}$ grade students. Characterized by this age's problems (nearly teenagers, nearly 13,14 or 15 years old), these students are more likely to reflect negative reactions in the school environment as well as in their homes. Two or three students in each class seem to reflect such behaviors, they belong mainly to that category of students who have continuously been characterized by low school progress. In such situations educators need to be tactful when consulting school pupil's problems with their parents. When facing this group of students, both parents and teachers' collaboration should focus not only on their school achievement but even on their psychological development and problem solving of such difficulties. Only in this way would positive "psychological care and treatment of this group age" . (Hornby, 2011, p.105-106) characterized by teenage troubles, reduce undesirable behaviours and contribute positively to the establishment of positive rules in the classroom not distorting the teaching process.

\section{Activities Increasing Parent's Involvement}

It is to be accepted that there is a lack of parents' involvement in schools regarding children's education. Since this current parent involvement goes beyond contributing candies and sweets to class parties as it usually happens, it is the teachers' and school's responsibility to do the utmost in increasing parents' participation and collaboration in their children's education. Schools' directories or individual teachers can:

- Plan annual activities early in the school year that serve to introduce families and school teachers in a positive 
setting, rather than waiting until problems arise from pupils.

- Teachers can provide parents with periodic updates of pupils' class activities and assignments by applying any of the above mentioned strategies.

- Schools can sponsor presentations or workshops (made by teachers themselves) for parents to support their child's education. This would undoubtedly give a sense of familiarity between teachers and parents breaking in this way the barriers between the educators and parents.

- One innovative strategy to be applied in our schools would be the preparation of a Parent-Teacher conference. It could be organized at least once a year. The decision of topics for discussion could also be an agreement between the three teachers-parents-pupils, setting in this way responsibilities to each of them, at the meantime also increasing collaboration among the three of them. ("Building partnerships between parents and practitioners", n.d. p.14-15)

The application of such strategies would subsequently lead to the elaboration of common plans by both educators and parents in enhancing students' progress, in reducing pupils' misbehaviors and in increasing lesson efficiency due to the creation of a positive well managed classroom environment.

\section{Conclusion}

Parent-teacher partnership is emphasized to be an effective means of fostering students success in a well managed classroom environment. Effective communication is crucial in establishing these strong useful knots between school and home, these two fundamental institutions, equally sharing the responsibility of contributing to the children's progress. Research has proved that when parents and teachers work together, everyone benefits: students tend to earn higher grades, perform better on tests, attend school more regularly, have better behavior, and show more positive attitudes toward themselves and toward school.

Finally it is to be emphasized that every communication exchange between parents and educators, regardless of its format (whether it is a note, phone call, meeting etc) should be viewed as a carefully planned approach which would definitely support students' learning in a stimulating and encouraging classroom.

\section{References}

Bruce, D. How to involve parents in a multicultural school. USA. Published by ASCD.

"Building partnerships between parents and practitioners". n.d. , downloaded on 19.01.2015. http://www.ncca.biz/Aistear/pdfs/Guidelines ENG/Practitioners_ENG.pdf

Hornby, Garry. (2011). Parental Involvement in Childhood Education. "Building effective school-family partnerships". USA. Springer.

Porter, L. (2008). Teacher parent collaboration. "Early childhood to Adolescence". Australia. ACER Press.

Rogers, B. (2011). You know the fair rule (Third Edition). Australia. ACER Press.

"School, Family, and Community Partnerships". n.d. downloaded on 18.01.2015. http://www.brown.edu/academics/educationalliance/sites/brown.edu.academics.education-alliance/files/uploads/KLOOM_sfcp_entire.pdf 